$13^{\text {th }}$ International Conference on

AEROSPACE SCIENCES \& AVIATION TECHNOLOGY,

ASAT- 13, May 26 - 28, 2009, E-Mail: asat@mtc.edu.eg

Military Technical College, Kobry Elkobbah, Cairo, Egypt

Tel : +(202) $24025292-24036138$, Fax: +(202) 22621908

\title{
Behavior of Composite Steel-Concrete Girders in Fire Condition
}

\author{
A. T. Kassem ${ }^{*}$, A. F. Hassan ${ }^{* *}$, and M. M. Seddeek ${ }^{* * *}$
}

\begin{abstract}
Fires have a highly destructive effect on steel structures. Steel-concrete composite elements have better fire resistance than bare steel, but the composite behavior differs a lot in fire than at normal conditions. This paper studies the flexural behavior of steel-concrete composite simply supported girders in fire condition. A three dimensional nonlinear thermalstructural finite element model has been established using COSMOSM software package to evaluate both girder structural and thermal responses in fire condition. Temperature distribution, mid-span deflection, and stresses in both steel beam and concrete slab have been introduced as functions of time. Results of the finite element model have been verified against experimental work and analytical models found in the available literature. The proposed model proved an accepted correlation with the available experimental work. A parametric study based on the outputs of this model has been performed to study effects of variations in various structural parameters on the behavior of composite girders. Practical conclusions about fire endurance, recommended load ratios, and best composite configurations have been extracted.
\end{abstract}

Keywords: steel, concrete, composite, beam, slab, girder, ISO 834 fire curve, material nonlinearity, mid-span deflection

\section{Introduction}

Structural fire engineering studies mainly the behavior of structures in fire. The main question that seeks a reply in that branch of science is "for how long could a structure with a specific configuration survive a pre-described fire load considering specific failure criteria?". Many analytical approaches have been presented in the past few decades to model the behavior of structures in fire. Rankine [1] approach is of the most famous models, where it basically concerns thermal effects leading to deterioration in material properties. It has been built on a simple interaction between idealized structural behaviors, strength, and stability criteria. It is famous for its simplicity where it considers that temperature distribution is uniform within individual members; structural elements are straight, isotropic, and prismatic; members buckle in plane of frame only; local and lateral torsional buckling are out of consideration; and working loads are concentrated. W.S. Toh [2] presented classical and numerical methods for evaluating fire resistance of steel frames considering the plastic theory. This theory could predict failure of a frame structure by tracing the development of plastic hinges until a mechanism is formed.

\footnotetext{
Teacher Assistant, Misr University for Science and Technology, $6^{\text {th }}$ October-Egypt, abdelraoufkassem@yahoo.com

** Associate Professor, Cairo University, Giza-Egypt, afarouk@cosmos-eng.com

${ }^{* * *}$ Professor of Structures, Cairo University, Giza-Egypt, mconsult@mconsult1.com
} 
Famous experimentations on full scale structures have been performed at the fire Engineering Laboratory in Cardington - England [3], Technical university of Braunschweig Germany[4], and the Laboratory of steel structures, Helsinki university of technology in Espoo [5]; but due to the high cost of such experimental programs, and the lack of essential installations and full scale totally equipped fire compartments in most structural research laboratories a great need for finite element modeling techniques and structural fire oriented software has arisen. Some ready made software packages, as Vulcan [6], STABA-F [6], ADAPTIC [6], and FEAST [6] have been developed. This paper presents a non-linear finite element model for full shear connected steel-concrete composite girders subjected to predescribed fire loads. The finite element model has been developed using "COSMOS/M 2.9" [7] that contains structural and heat transfer modules and can non-linearly model structures with temperature dependent material properties.

\section{Finite Element Model}

A three dimensional finite element model has been developed. The model consists of fully connected solid elements representing steel beam and concrete slab. Finer meshes have been utilized at zones of stress concentration. The simply supported girder has been divided longitudinally to 96 elements. Figure (1) shows the problem main geometry, while figure (2) shows a cross-section of the model. Elements chosen for modeling could support both thermal and structural analyses. Modeling main assumptions could be summarized as follows:

1- Full shear connection has been performed between steel beam and concrete slab.

2- Steel was considered elasto-plastic, isotropic material [8].

3- Concrete was considered elasto-plastic, isotropic (subjected to compression, so no cracks occur) material.

4- Steel and concrete material non-linearities due to elevated temperature were considered in accordance with Euro code [9], [10], [11], [12].

5- Furnace gas temperature was considered in accordance with the standard fire curve (ISO 834) [13].

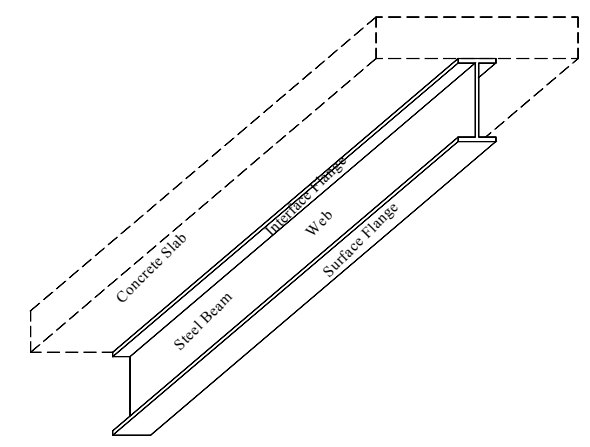

Figure (1) Composite Girder Geometry

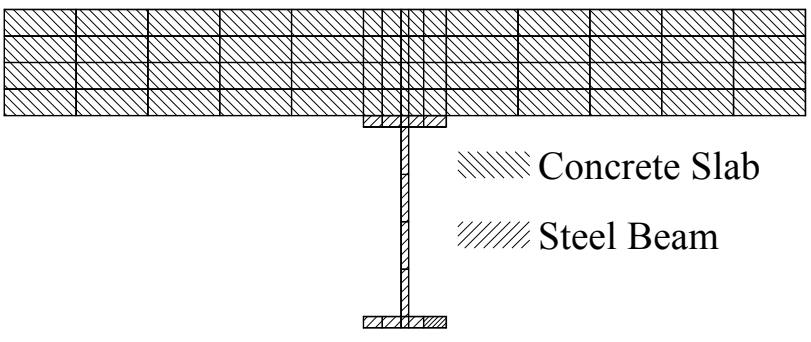

Figure (2) Finite Element Model

\section{Solving Procedure}

Solving the problem was divided into two phases. The first phase concerned the heat transfer module, where a convection-radiation [14] thermal load in accordance with the ISO 834 fire curve was applied to the girder soffit. 
Transient heat transfer analysis was performed in order to stand on the temperature distribution within the composite girder due to the applied thermal load. Table (1) states ambient temperature material properties, while figures (3) up to (7) show material degradation factors due to increase in temperature.

Table (1) Ambient Temperature Structural and Thermal Parameters

\begin{tabular}{|l|c|c|c|}
\hline Parameter & Steel & Concrete & Unit \\
\hline Strength & $240^{(16)}$ & $35^{(17)}$ & $\mathrm{MPa}$ \\
\hline Elasticity Modulus & $2.1 \times 10^{5(16)^{-}}$ & $26030^{(17)}$ & $\mathrm{MPa}$ \\
\hline Poisson's Ratio & $0.3^{(16)}$ & $0.2^{(17)}$ & - \\
\hline Density & $7800^{(16)^{-}}$ & $2500^{(17)}$ & $\mathrm{Kg} / \mathrm{m}^{3}$ \\
\hline Coeff. of Thermal Expansion & $1.2 \times 10^{-5(16)^{-}}$ & $1 \times 10^{-5(17)}$ & $\mathrm{T}$ \\
\hline Specific Heat & $600^{-13)^{-}}$ & $900^{(13)}$ & $\mathrm{J} / \mathrm{kg} \mathrm{k}$ \\
\hline Thermal Conductivity & $54^{(13)}$ & $1.33^{(13)}$ & $\mathrm{w} / \mathrm{m} \mathrm{k}$ \\
\hline
\end{tabular}

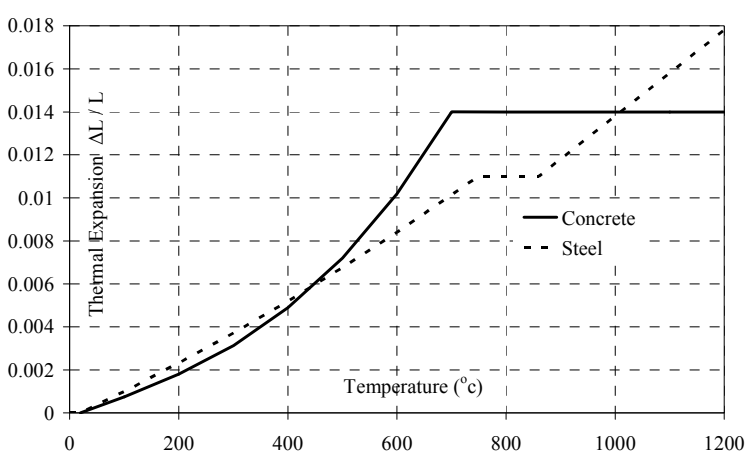

Figure (3) Thermal Expansion at High Temperatures [12]

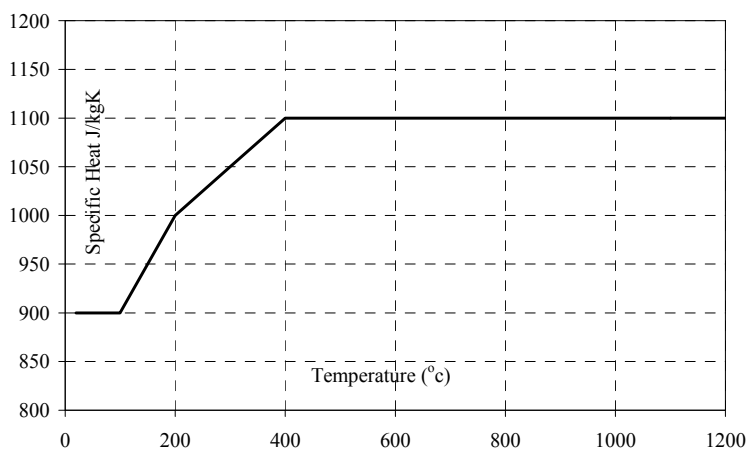

Figure (5) Concrete Specific Heat [10]

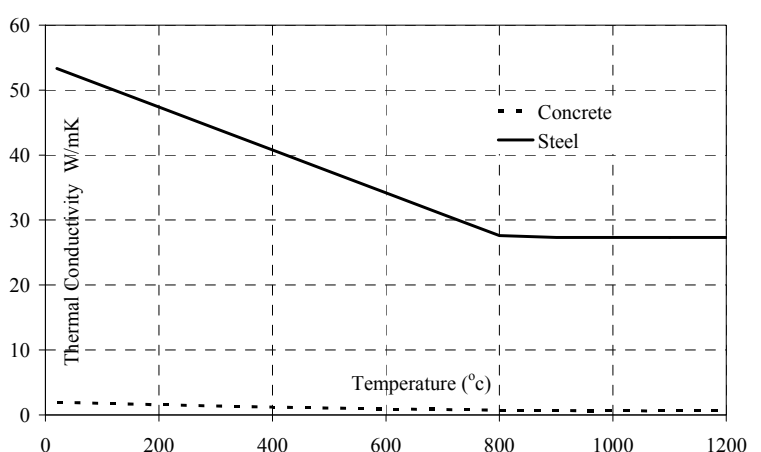

Figure (4) Thermal Conductivity [12]

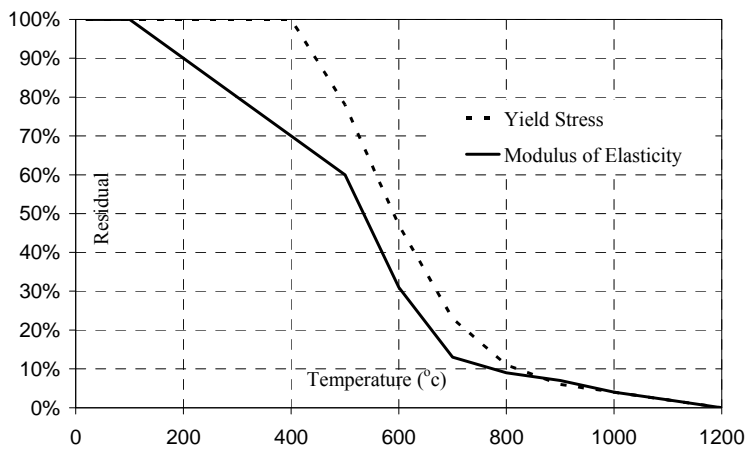

Figure (6) Steel Degraded Structural Properties [11] 


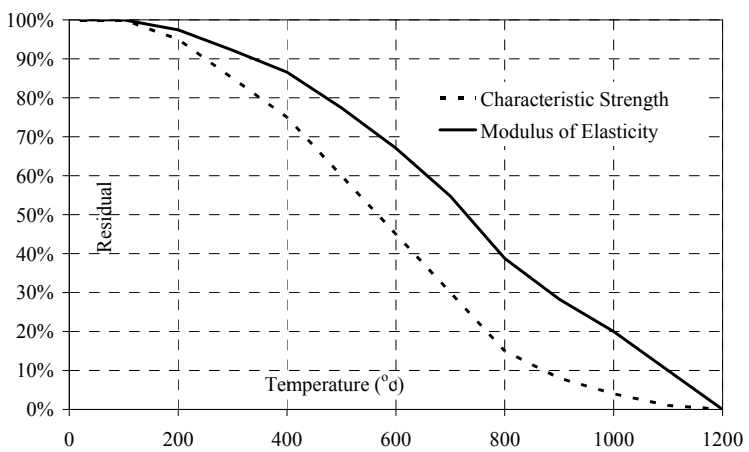

Figure (7) Concrete Degraded Structural Properties [10]

The second phase concerned the solution of the structural problem where own weight and superimposed loads had been applied to the model, then thermal loads were applied. The structural analysis was performed for each thermal load increment considering temperature distribution generated as an output of the first analysis phase in combination with superimposed loads.

\section{Model Verification}

In order to judge the reliability of the proposed model it has been verified against experimental and theoretical work found in the available literature [3, 15], where two experiments have been performed according to the configuration shown in figure (8), subjected to a thermal loads applied to girder's soffit according to the standard ISO 834 fire curve as shown in figure (9). Mid-span deflection has been measured experimentally and predicted mathematically.

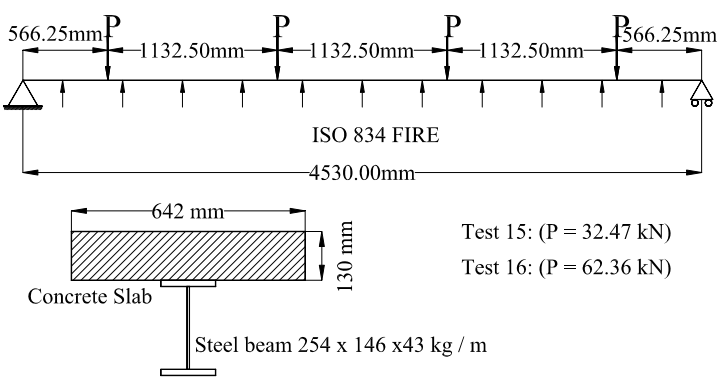

Figure (8) Experimental Test Setup [15]

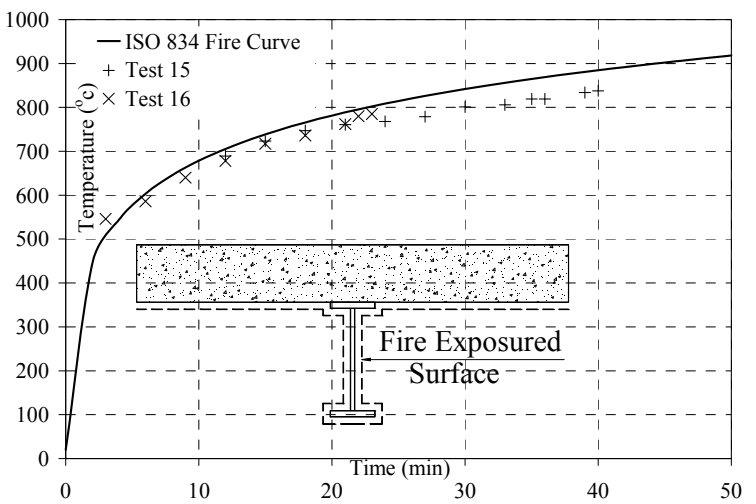

Figure (9) Tests (15) and (16) Fire Loads [15]

Temperature profile was recorded at different time intervals. Figures (10) and (11) show experimentally recorded and mathematically predicted temperature profiles based on the proposed model across the girders cross-sections from the beginning of thermal load application up to failure. It could obviously be seen that temperature of web is higher than flanges, and that refers to the higher section factor $\left(\mathrm{A}_{\mathrm{s}} / \mathrm{V}\right)$ of the web relative to flanges. It could be noticed that temperature of the upper flanges is less than the lower one, this refers to section modulus too, where the lower flange is heated from four surfaces while the upper 
is heated from three surfaces only, as its upper surface is protected due to its contact with the concrete slab. It could also be noticed that damping takes place rapidly to temperature within the concrete slab due to its low thermal conductivity.

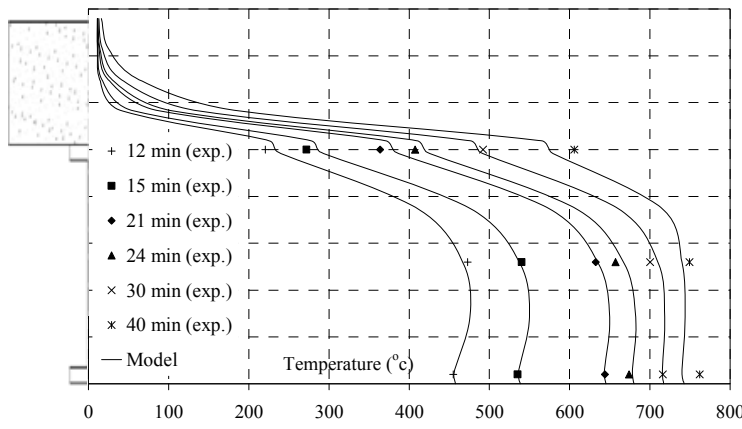

Figure (10) Test (16) Thermal Verification

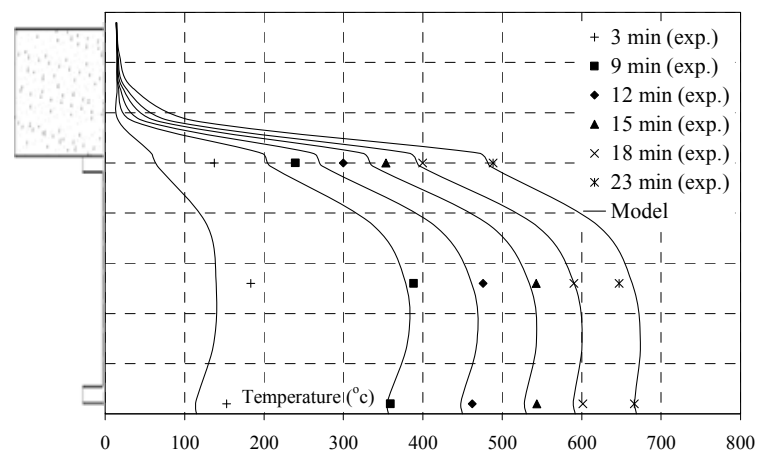

Figure (11) Test (15) Thermal Verification

As concrete slab temperatures has not been recorded experimentally in neither test (15) nor test (16), verification of the thermal model for concrete slab has been performed by modeling a concrete slab of thickness $200 \mathrm{~mm}$ subjected to Standard fire (ISO 834) and comparing the outputs with figure available in Eurocode [10] as shown in figure (12).

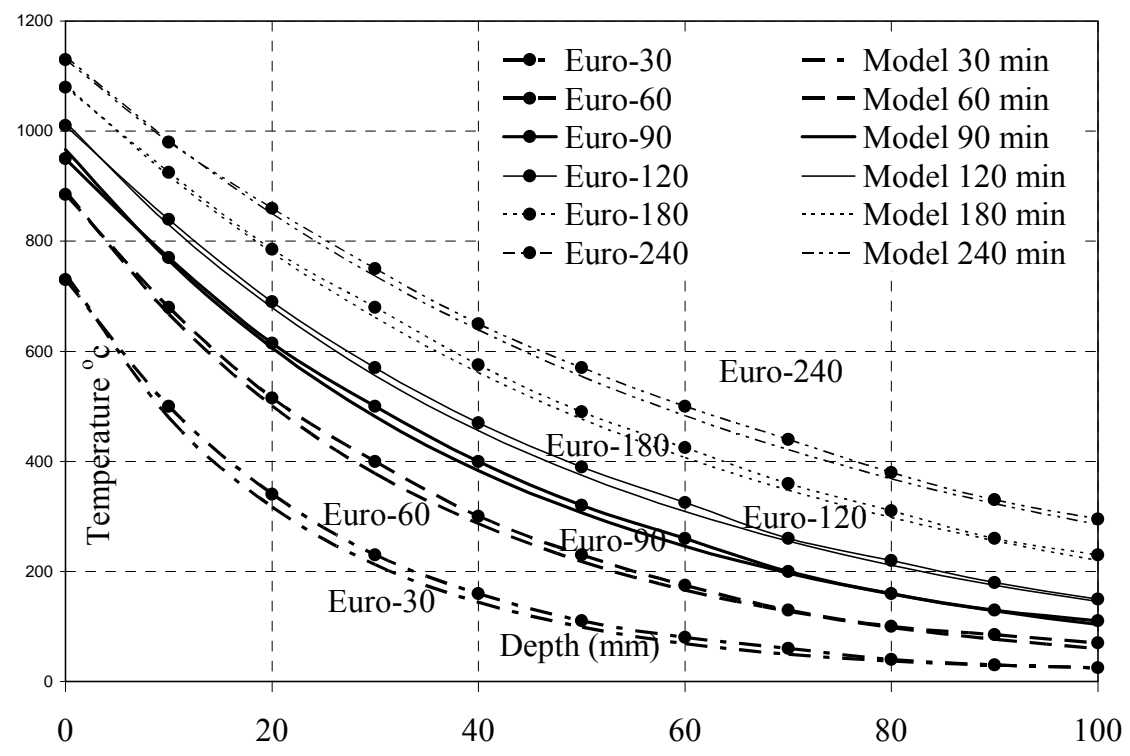

Figure (12) Concrete Slab Thermal Verification [10]

Figures (13) and (14) show a comparison between mid-span deflection measured experimentally; and estimated by Zhaohui [3], and the proposed model for tests (15) and (16) respectively. It could be obviously noticed that the proposed model could well estimate deflection history of test (16) till failure. Meanwhile both the proposed model and that of Zhaohui [3] could estimate deflection history till about $70 \%$ of failure time for test (15), this refers to the presence of a kink in the degradation curve of steel modulus of elasticity at $700^{\circ} \mathrm{c}$; that lower flange in test (15) reached due to its low load ratio, while test (16) failed before due to its high load ratio. 


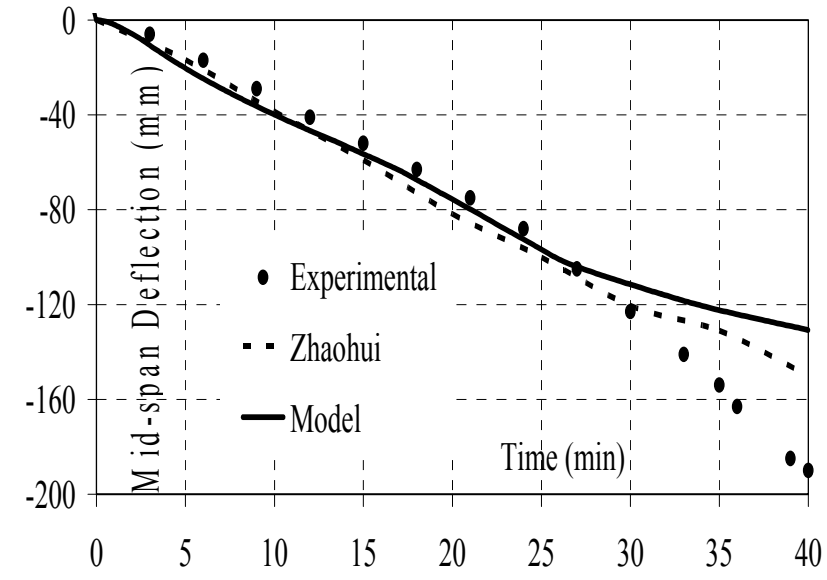

Figure (13) Test (15) Mid-span Deflection [3]

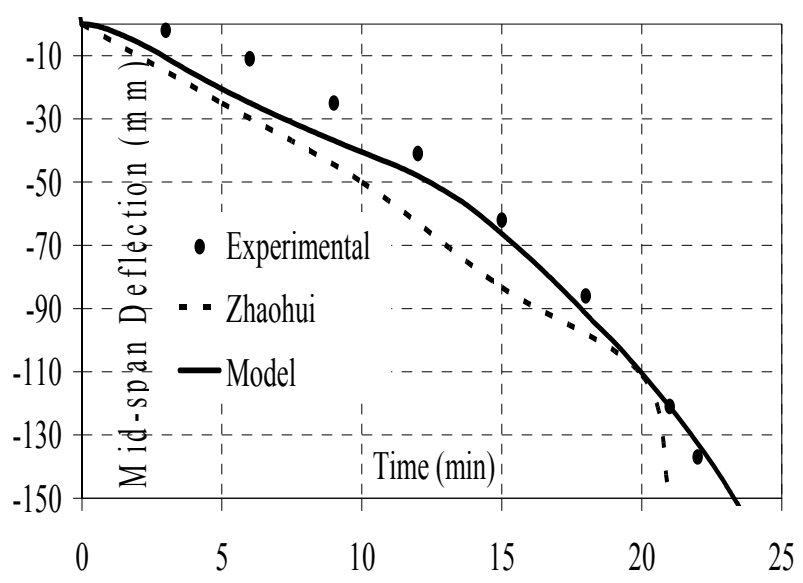

Figure (14) Test (16) Mid-span Deflection [3]

\section{Thermal-Structural Behavior}

Stresses and strains in both steel beam and concrete slab have been introduced as functions of time. Stresses of test (16) have been studied in detail as shown in figure (15), where stress history could be divided into four main stages as discussed herein after.

\section{Stage I (Super-imposed Loads)}

In this stage tensile stresses take place at steel surface flange and compressive or tensile stresses take place at steel interface flange, according to location of neutral axis.

\section{Stage II (Pre-degradation, Super-imposed Combined with thermal Loads)}

As temperature of steel surface flange is higher than interface flange and concrete slab; girder's lower surface expands more than upper surface and sagging takes place, leading to an increase in both surface tensile and interface compressive stresses.

\section{Stage III (Post-degradation, pre-yield)}

As temperature increases, modulus of elasticity decreases; and consequently normal stress for the same strain decreases. This leads to a decrease in the rate of increase of normal stress.

\section{Stage IV (Post-degradation, post-yield)}

In this stage material enters the yield plateau where stresses are retained around the yield level, this decreases by default as temperature increases; this leads to a decrease in normal stresses. 


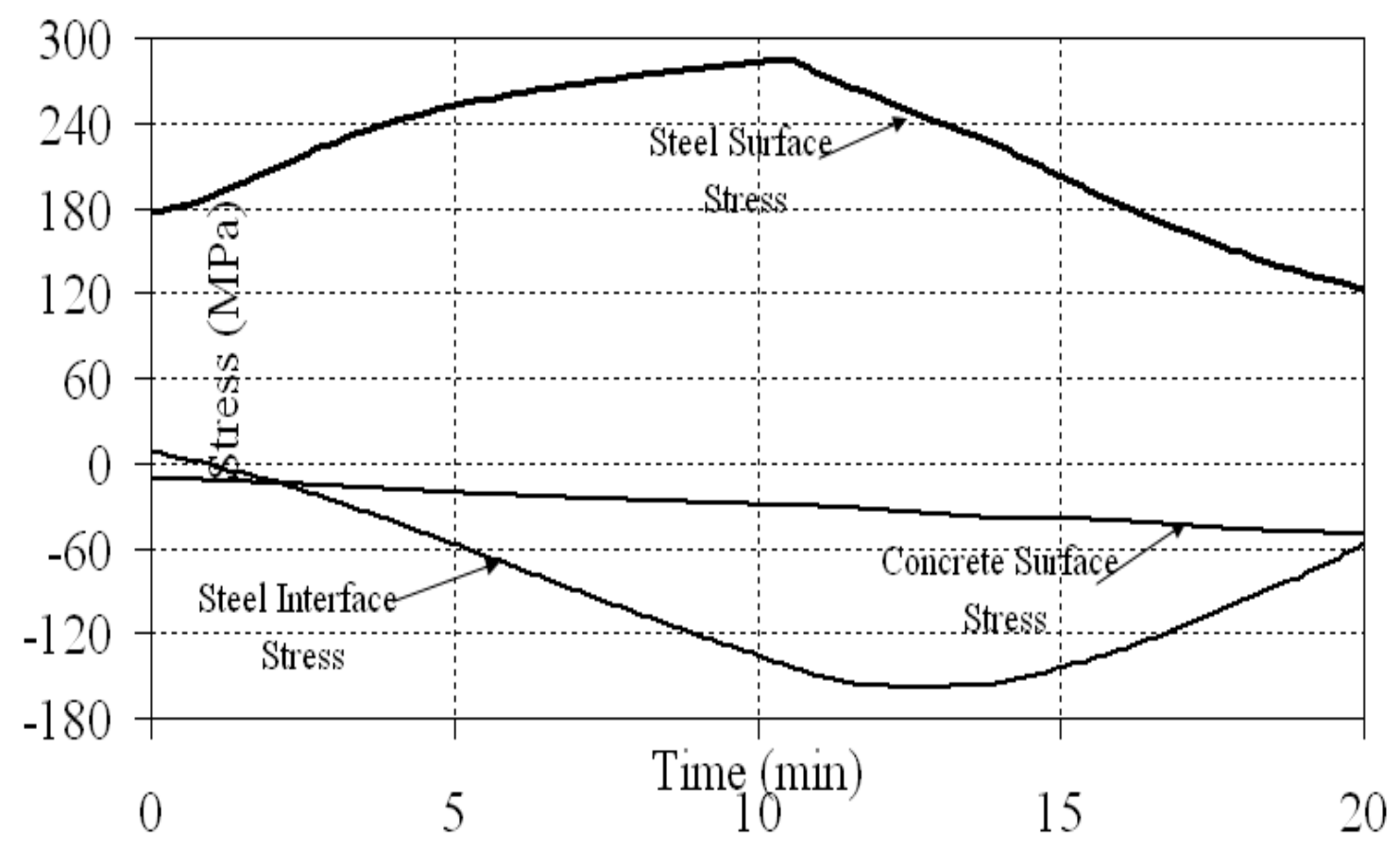

Figure (15) Test (16) Stress History

\section{Parametric Studies}

In order to clarify effects of various structural parameters on the behavior of composite girders in fire (5) main parametric studies have been performed, to study effects of end condition, load ratio, material properties, geometric configuration, and stiffness, in which (12) models have been established. Deflection that equals $\mathrm{L} / 30$ has been considered a failure criterion of [12]. Table (2) summarizes technical data of girders used in the parametric Studies.

\section{End Condition}

Building's girders are usually designed simply supported (hinge-roller) and constructed with longitudinal restraints (hinge-hinge). The presence of longitudinal restraints generates additional stresses when the girder is subjected to a thermal load. Model (M2) represents a girder longitudinally restrained at the beam soffit, while model (M3) represents restraints near the neutral axis.

Figure (16) shows mid-span deflection for models (M1), (M2), and (M3). Model (M2) faced a sharp failure a low deflection. It faced a high compressive stress on the whole section, compression in the interface flange due to flexural loads and in the surface flange due to longitudinal restraint against deformations and thermal expansion. Model (M3) behaved in a pattern that resembles model (M1), but higher deflection appeared after 7 and up to 26 minutes, due to the excessive compression at the restrained interface flange, leading to a sagging moment. After awhile difference in temperatures between surface and interface flanges decreases, hence slope angle decreases and sagging moment also decreases, this decreases the rate of increase in deflection that increases due to degradation of structural material properties. 
Paper: ASAT-13-CV-21

Table (2) Parametric Studies Technical Data

\begin{tabular}{|c|c|c|c|c|c|c|c|c|c|c|c|c|c|c|c|}
\hline \multirow{5}{*}{$\begin{array}{c}\text { Parametric } \\
\text { Studies } \\
\text { Objectives }\end{array}$} & \multirow{4}{*}{$\frac{\infty}{\frac{\infty}{0}}$} & \multicolumn{9}{|c|}{ Geometric Data $(\mathrm{mm})$} & \multicolumn{4}{|c|}{ Structural Data (Mpa) } & \multirow{4}{*}{ 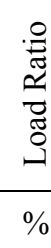 } \\
\hline & & \multicolumn{6}{|c|}{ Steel Beam } & \multirow{2}{*}{\multicolumn{2}{|c|}{$\begin{array}{l}\text { Concrete } \\
\text { slab }\end{array}$}} & \multirow{3}{*}{$\begin{array}{c}\text { Span } \\
\mathrm{L} \\
\end{array}$} & \multirow{2}{*}{\multicolumn{2}{|c|}{ Steel Beam }} & \multirow{2}{*}{\multicolumn{2}{|c|}{$\begin{array}{l}\text { Concrete } \\
\text { slab }\end{array}$}} & \\
\hline & & \multicolumn{2}{|c|}{$\begin{array}{c}\text { Surface } \\
\text { flange }\end{array}$} & \multicolumn{2}{|c|}{ Web } & \multicolumn{2}{|c|}{$\begin{array}{c}\text { Interface } \\
\text { flange }\end{array}$} & & & & & & & & \\
\hline & & $\mathrm{b}_{\mathrm{sf}}$ & $\mathrm{t}_{\mathrm{sf}}$ & $\mathrm{b}_{\mathrm{w}}$ & $\mathrm{t}_{\mathrm{w}}$ & $\mathrm{b}_{\text {if }}$ & $\mathrm{t}_{\text {if }}$ & $\mathrm{b}_{\mathrm{cs}}$ & $\mathrm{t}_{\mathrm{cs}}$ & & $\mathrm{f}_{\mathrm{y}}$ & $\mathrm{E}_{\mathrm{s}}$ & $\mathrm{f}_{\mathrm{cu}}$ & $\mathrm{E}_{\mathrm{c}}$ & \\
\hline & M1 & 215 & 32 & 535 & 22 & 215 & 32 & 1500 & 200 & 20000 & 240 & 210000 & 35 & 26031 & 64 \\
\hline End & M2 & 215 & 32 & 535 & 22 & 215 & 32 & 1500 & 200 & 20000 & 240 & 210000 & 35 & 26031 & 64 \\
\hline Condition* & M3 & 215 & 32 & 535 & 22 & 215 & 32 & 1500 & 200 & 20000 & 240 & 210000 & 35 & 26031 & 64 \\
\hline load ratio & M4 & 215 & 32 & 535 & 22 & 215 & 32 & 1500 & 200 & 20000 & 240 & 210000 & 35 & 26031 & 32 \\
\hline Material & $\mathrm{M} 5 * *$ & 215 & 32 & 535 & 22 & 215 & 32 & 1500 & 200 & 20000 & 240 & 210000 & 140 & 52062 & 64 \\
\hline Properties & M6 & 215 & 32 & 535 & 22 & 215 & 32 & 1500 & 200 & 20000 & 360 & 210000 & 35 & 26031 & 64 \\
\hline & M7 & 430 & 16 & 568 & 18 & 430 & 16 & 1500 & 200 & 20000 & 240 & 210000 & 35 & 26031 & 64 \\
\hline Geometric & M8 & 108 & 65 & 470 & 30 & 108 & 65 & 1500 & 200 & 20000 & 240 & 210000 & 35 & 26031 & 64 \\
\hline Configura- & M9 & 215 & 32 & 535 & 22 & 108 & 32 & 1500 & 200 & 20000 & 240 & 210000 & 35 & 26031 & 64 \\
\hline & M10 & 215 & 32 & 535 & 22 & 215 & 32 & 12000 & 100 & 20000 & 240 & 210000 & 35 & 26031 & 64 \\
\hline stif & M11 & 215 & 32 & 535 & 22 & 215 & 32 & 1500 & 200 & 10000 & 240 & 210000 & 35 & 26031 & 64 \\
\hline $\sin$ & M12 & 215 & 32 & 535 & 22 & 215 & 32 & 1500 & 200 & 5000 & 240 & 210000 & 35 & 26031 & 64 \\
\hline
\end{tabular}

* As (M1), but with different end conditions.

** Concrete characteristic strength had been increased to four folds and consequently modulus of elasticity has been doubled as $E_{c} \propto \sqrt{f_{c u}}$

\section{Load Ratio.}

Load ratio represents to what extent the girder is subjected to stresses, it is the ratio between applied and yield stresses, two load ratios were chosen (64\% and $32 \%)$, represented by models (M1) and (M4) respectively.

Figure (17) shows mid-span deflection for models (M1) and (M4). Where a reduction of load ratio by $50 \%$ lead to an increase in fire endurance by about $16 \%$.

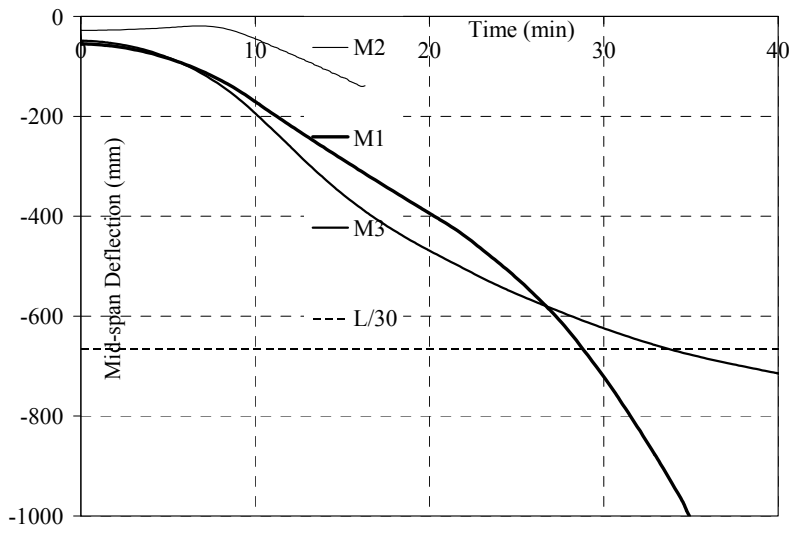

Figure (16) (M1), (M2), and (M3) Mid-span Deflection

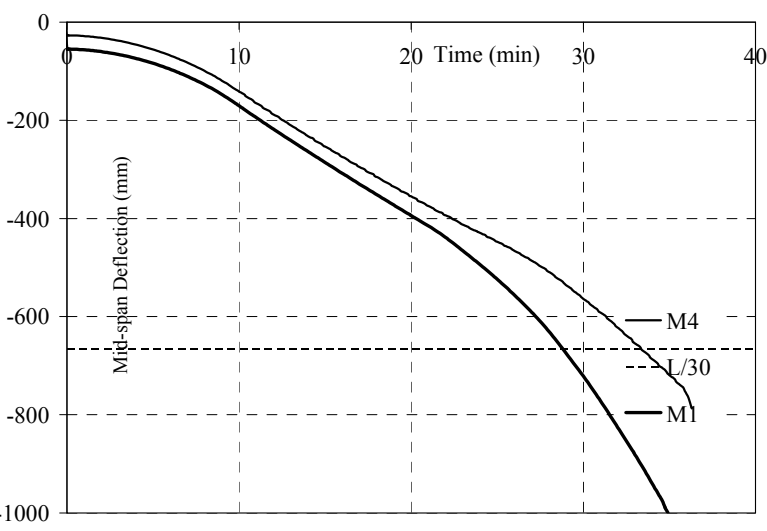

Figure (17) (M1), and (M4)-Mid-span Deflection 


\section{Materials Strength Characteristics.}

Effects of change of concrete characteristic strength, and hence modulus of elasticity; and steel yield stress have been studied using Models (M5) and (M6) respectively. Figure (18) shows mid-span deflection versus time for models (M1), (M5), and (M6). It is obvious that variations in values of deflection for the same time are minor, it could be noticed that increasing concrete characteristic strength and hence modulus of elasticity lead to an increase in fire endurance beyond the pre-determined failure criterion of $\mathrm{L} / 30$, where concrete bears a larger portion of load as steel looses most of its stiffness.

\section{Section Factor.}

Section factor is a physical quantity of dimensions $\mathrm{L}^{-1}$. It represents the ratio of the exposure surface relative to the total volume of the structural element. Models (M1), (M7), and (M8) represent section factors of $0.07,0.10$, and 0.05 respectively and (M1) represents an intermediate value of 0.079. Figure (19) shows mid-span deflection for models (M1), (M7) and (M8). It could be noticed that fire endurance is about to be linearly proportional to the section factor and proportionality constant increases by time as temperatures increases and stiffness degrades.

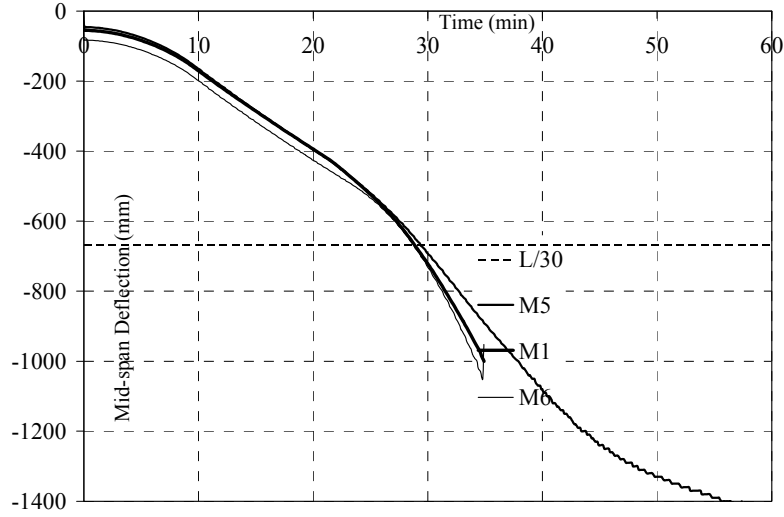

Figure (18) (M1), (M5), and (M6) Mid-span Deflection

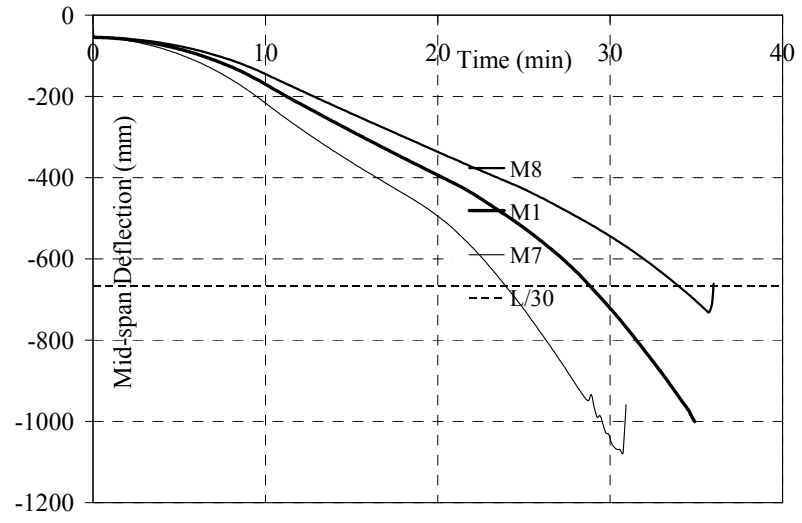

Figure (19) (M1), (M7), and (M8) Mid-span Deflection

\section{Usage of Small Interface (Upper) Flange.}

Composite girders are usually designed with a smaller interface flange due to the contribution of concrete slab in bearing loads so two alternatives were chosen, one with equal compression flanges, and other with interface flange width half that of surface one, represented by models (M1) and (M9) respectively.

Figure (20) shows mid-span deflection for models (M1) and (M9). It could be noticed that using a small interface flange has no significant effect on the behavior of composite girder; this is due to the location of the interface flange near the neutral axis, resulting in small strains and consequently small stresses or a small portion of load to be sustained by the interface flange.

\section{Slab configuration}

Slab configuration is a term that refers to the concrete slab cross-sectional aspect ratio. Two aspect ratios of (7.5) for model (M1) and (120) for model (M10) had been chosen. Figure (21) represents mid-span deflection for models (M1) and (M10). It could be concluded that concrete aspect ratio has no influence on fire endurance of composite girders. This refers to 
concrete low thermal conductivity and high specific heat; leading low slab temperature and hence consistent structural properties as approximately material degradation does not take place.

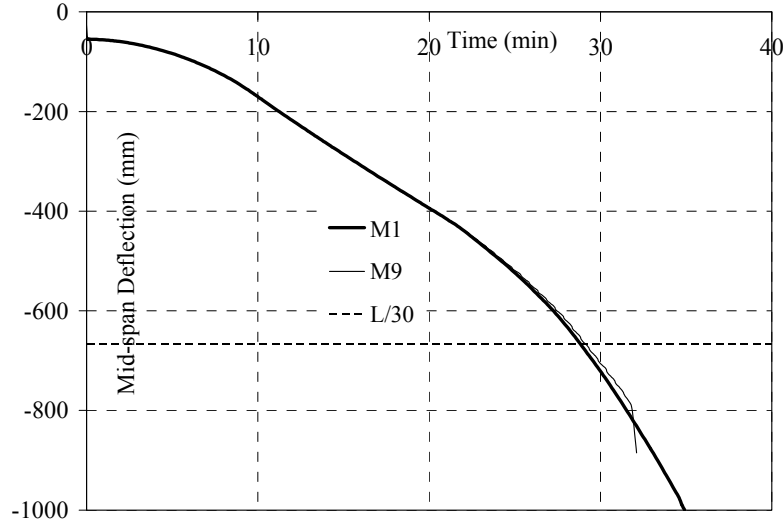

Figure (20) (M1), and (M9) Mid-span Deflection

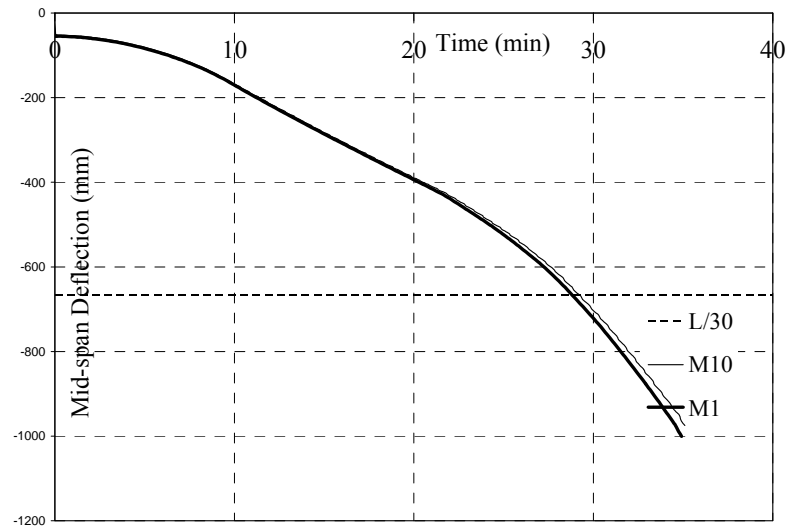

Figure (21) Models (M1) and (M10) Mid-span Deflection

\section{Length to section modulus ratio.}

Length to section modulus ratio is an important design parameter, where the initial choice of a cross-section is performed based on common values of that parameter. Three values of $(\mathrm{L} / \mathrm{Z})$ were chosen $2.71 \times 10^{-3}, 1.36 \times 10^{-3}$, and $6.78 \times 10^{-4}$ represented by models (M1), (M11), and (M12) respectively. It was found that sections with low rigidity fail in a ductile pattern, where large tensile strain takes place at the steel surface flange, leading to a large deflection. While sections with high rigidity fail suddenly before significant strains take place. Figure (22) shows deformed shapes at failure for models (M1), (M11), and (M12) respectively.

Figure (23) shows mid-span deflection for models (M1), (M11), and (M12) respectively. It could be noticed that models (M11) and (M12) failed even before reaching the failure criterion of $(1 / 30)$.

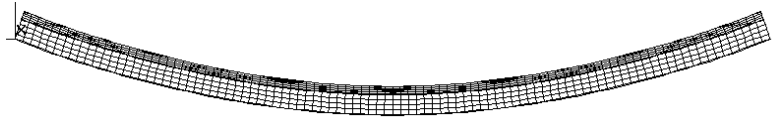

(M1)

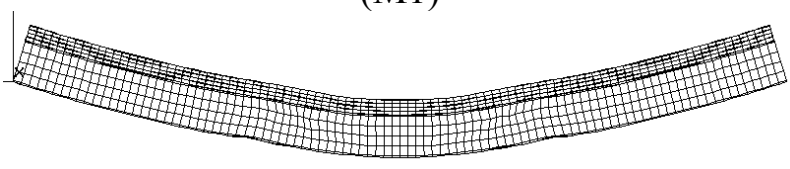

(M11)

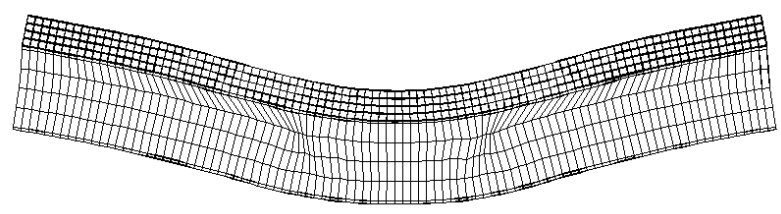

(M12)

Figure (22) Deformed shapes at failure for Models (M1), (M11), and (M12) respectively

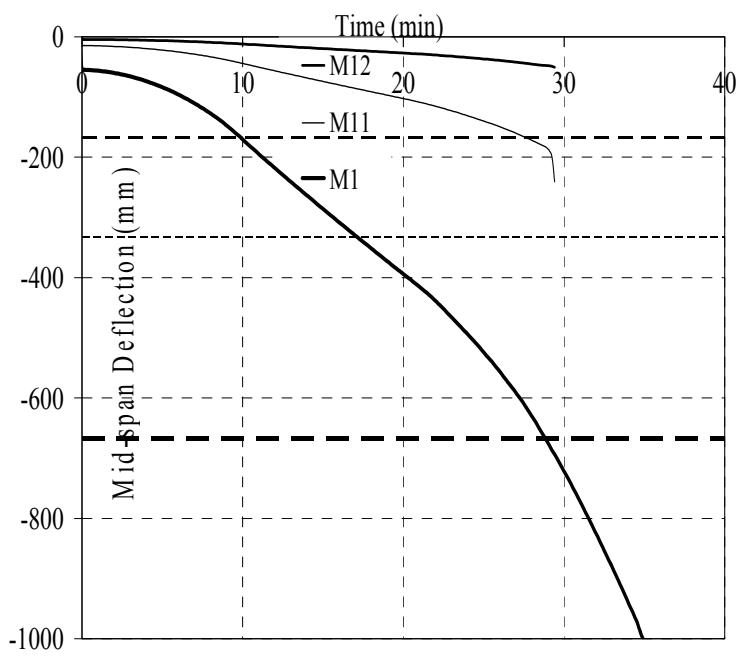

Figure (23) Models (M1), (M11), and (M12) Mid-span Deflection 


\section{Conclusions}

1- The proposed model could well predict thermal and structural behaviors of the composite girders compared to experimental data found in the available literature.

2- The presence of longitudinal restraints passively affects the behavior of composite girders in fire condition.

3- Composite girders restrained near the neutral axis behave much better than girders restrained at the steel soffit.

4- The less the load ratio the more the fire endurance

5- The more the concrete stiffness relative to steel the more the fire endurance even after a subjective failure criterion.

6- Steel grade does not affect structural behavior in fire condition.

7- Fire endurance is linearly proportional to girder section factor.

8- Usage of a small interface flange does not passively affect the behavior of composite girder in fire.

9- Concrete slab configuration is an insignificant parameter for a problem of a composite girder in fire condition.

10-Bernoulli beams (low stiffness) behave in a ductile pattern in fire conditions, while deep beams behave in a brittle pattern.

\section{References}

[1] Toh, W.S., Tan, K.H. and Fung, T.C. "Strength And Stability of Steel Frames in Fire: Rankine Approach" ASCE Journal of Structural Engineering, 2001, V. 127, pp. 461469

[2] Toh, W.S. Fung, T.C. and Tan, K.H. "Fire Resistance of Steel Frames Using Classical and Numerical Methods" ASCE Journal of Structural Engineering, 2001, V. 127, pp. 829-838.

[3] Zhaohui Huang, Ian Burgess, and Roger J.Plank, "Three-Dimensional Analysis of Composite Steel-Framed Buildings in Fire" ASCE Journal of Structural Engineering, 2000, V. 126, pp. 389-397.

[4] Lynn S Beedle, Dolores B. Rice, "Fire Safety in Tall Buildings" Council on Tall Buildings and Urban Habitat, 1992, Lehigh University, Bethlehem, Pennsylvania,

[5] Ma,Z and Makelainen, "Fire Safety Design of Composite Slim Floor Structures" Ph.D. Thesis, Helsinki University of Technology, Espoo, 2000.

[6] Wang, Y.C. "STEEL AND COMPOSITE STRUCTURES, Behaviour and design for fire safety ," SPON PRESS, Taylot \& Francis Group, London and New York, 2005.

[7] COSMOS/M 2.9 "Finite Element Computer Program Manual", Structural Research and Analysis Corporation 2004

[8] Rees, D.W.A. "Basic Engineering Plasticity" Elsevier, UK,2006.

[9] Euro code 1 EN-1991-1-2, "Actions on Structures-General Rules-Structural Fire Design ".

[10] Euro code 2 EN-1992-1-2, "Design of Concrete Structures-General Rules-Structural Fire Design".

[11] Euro code 3 EN-1993-1-2, "Design of Steel Structures-General Rules-Structural Fire Design".

[12] Euro code 4 EN-1994-1-2, "Design of Composite Steel And Concrete StructuresGeneral Rules-Structural Fire Design".

[13] Andrew H. Buchanan, "Structural Design for Fire Safety," JOHN WIELY \& sons, LTD Publication, NEW YORK,2005.

[14] Holman, J.P., "Heat Transfer," Ninth edition, McGraw-Hill, 2002. 
[15] Wainman, D.E. and Kirby, B.R. "Compendium Of Uk Standard Fire Test Data" BSC Swiden Laboratories, Technical Report No. RS/RSC/S10328/1/87/B.,1988

[16] ECOP, "Egyptian Code of Practice For Steel Construction And Bridges", Allowable Stress Design, Permanent Committee for the Code of Practice, Arab Republic of Egypt,2001.

[17] ECCS 203, "The Egyptian Code for Design and Construction of Reinforced Concrete Structures", Arab Republic of Egypt,2001. 